\title{
O PARADIGMA EMERGENTE E O ENSINO DO DIREITO
}

\section{Ney José de Freitas}

Mestre em Direito pela PUC/PR e Doutorando pela UFPR, Professor de Direito Administrativo (licenciado) da PUC/PR, Professor na área de Especialização das Universidades Tuiuti e de Ponta Grossa, Faculdade de Direito da Unibrasil e Faculdade de Direito de Curitiba, Juiz do Tribunal Regional do Trabalho da $9^{\mathrm{a}}$ Região.

SUMÁRIO: 1 Paradigmas da Ciência; 2 Paradigmas Conservadores e a Reprodução do Conhecimento; 3 Paradigma Emergente e a Produção do Conhecimento; $4 \mathrm{O}$ Ensino do Direito e o Paradigma Emergente; 4.1 A Visão Holística; 4.2 O Paradigma Progressista; 4.3 Paradigma do Ensino com Pesquisa; Referências Bibliográficas.

\section{PARADIGMAS DA CIÊNCIA}

Por longo tempo vigorou na ciência o paradigma newtoniano-cartesiano, que apresentou como característica fundamental a fragmentação. A afirmação dessa forma de pensar o mundo surgiu em GALILEU GALILEI, com a concepção do denominado método científico (observação dos fenômenos, experimentação, regularidade matemática) idéia que se acopla com a visão de DESCARTES quando, no discurso do método - fundamentalmente -, preconiza que é preciso fragmentar para conhecer. Eis aí a origem, sem dúvida, do pensamento que predominou no mundo até o início do século: concepção mecanicista do mundo. Fragmentação. Separação completa entre corpo e mente. Emoção divorciada, por completo, da razão.

Essa visão do mundo provocou influência em todos os compartimentos da sociedade. No plano existencial, ${ }^{1}$ a ética individualista e os valores materiais cimentam a civilização do ter. Em outras palavras: ocorreu um notável progresso no campo da ciência e da técnica, mas, no campo do sentimento, houve uma paralisação com prejuízos incalculáveis para o progresso do homem.

Contudo, é preciso admitir que na vida nada possui caráter de definitividade. Tudo é processo. Movimento. Mudança. Alteração. Deste modo, como não poderia deixar de ser, também no que atine aos paradigmas da ciência ocorreu o mesmo fenômeno. A mudança de paradigma é sempre precedida de crises. Assim, o paradigma começa a sofrer um movimento erosivo em suas bases, provocando, por conseqüência, a sua derrocada. Dito de outra forma: os seus pilares enfraquecem, na medida exata em que o novo paradigma começa a surgir. Cabe esclarecer que a mudança de paradigma

1 CARDOSO, Clodoaldo Meneguello. A canção da inteireza. Uma visão holística da educação. São Paulo: Summus, 1995. 
não é algo instantâneo, pois, a mudança é sempre traumática, visto que implica no rompimento com o passado sem que o futuro esteja, ainda, delineado. Do mesmo sentir é $\mathrm{KUHN}^{2}$ quando assere que a formação do novo paradigma ocorre nas entranhas do anterior. E este, por sua vez, nunca desaparecerá totalmente. Escrevendo a respeito do tema, PIERRE WEIL ${ }^{3}$ teve a oportunidade de dizer que a crise é uma pré-condição para o aparecimento de novas teorias. Tem razão, sem dúvida, o notável Professor WEIL, pois da mesmice não nasce mudança. É imperioso que surja uma comunicação divergente, em desarmonia com o pensamento dominante para que se estabeleça a contradição, surja a crise e seja possível a mudança.

Surge, então, a ruptura. Segundo BEHRENS 4 "a ruptura de um paradigma decorre da existência de um conjunto de problemas, que os pressupostos vigentes na ciência não conseguem solucionar". O começo deste século foi o momento histórico apropriado para a mudança de paradigma. Tal mudança ocorreu no campo da biologia, física e química, como não poderia deixar de ser.

De fato, a ciência atual funda-se num paradigma que surgiu, de certo modo, com a introdução no campo científico das idéias de LAMARK (evolução a partir de formas primitivas sob a influência do meio), pensamento este que foi retomado e aperfeiçoado por CHARLES DARWIN (a evolução se verifica em decorrência de mutações que se produzem, seja por forma natural ou por cruzamento e estabilizam-se por seleção natural). De outra parte, no campo da física surgiu introduzida por PLANK e outros a denominada física quântica (1900) demonstrando que o mundo não pode ser decomposto em unidades elementares que existem de maneira independente. O que existe, na verdade, é uma complexa teia de relações entre as várias partes de um todo unificado. ${ }^{5}$ Em suma: a física quântica despreza a fragmentação para prestigiar o todo. Outro contributo importante foi oferecido por PRIGOGINE, por meio da sua teoria das estruturas dissipativas, quando afirma que "em sistemas vivos, que operam afastados do equilíbrio, os processos irreversíveis desempenham um papel construtivo e indispensável. A irreversibilidade é o mecanismo que produz a ordem a partir do caos". Não se pode esquecer, de outra margem, o pensamento de CAPRA quando oferece ao meio científico a sua concepção de rede, no livro "A teia da vida", com uma nova compreensão dos sistemas vivos, rejeitando a visão fragmentária do mundo e afirmando que a natureza do todo é sempre diferente da mera soma das suas partes. Ou seja: o todo está em cada uma das partes, como afirma CARDOSO. ${ }^{6}$

Este o quadro.

2 KUHN, Thomas. A estrutura da revolução científica. 4. ed. São Paulo: Perspectiva, 1996.

3 BRANDÃO, DENIS \& CREMA, Roberto. O novo paradigma holístico. São Paulo: Summus, 1991.

4 BEHRENS, Marilda Aparecida. O paradigma emergente e a prática pedagógica. 1. ed. Curitiba: Champagnat Universitária, 1999

5 CAPRA, Fritjaof. A teia da vida. Uma nova concepção científica dos sistemas vivos. São Paulo: Cultrix, 1996.

6 CARDOSO, op. cit., p. 49. 
Prevalece, hoje, uma visão do mundo de índole holística ou sistêmica. Abandonase, por completo, a idéia de fragmentação. Prepondera a perspectiva global, sistêmica, como uma nova forma de compreensão da vida.

\section{PARADIGMAS CONSERVADORES E A REPRODUÇÃO DO CONHECIMENTO}

A educação faz parte da dimensão humana. Nesta linha de princípio, cumpre investigar qual a influência de um paradigma conservador no campo da educação. Fundamentalmente, no âmbito de um paradigma conservador privilegia-se, sem dúvida, a reprodução do conhecimento. Meras repetições. Esquemas pré-moldados, onde o professor é o único detentor do conhecimento, oferecendo tal dádiva ao aluno que a recebe de forma pronta e acabada, sem qualquer participação de sua parte, aceitando silente a sua condição de ser receptivo e passivo, tão-só. "Leia, escute, decore e repita" é a síntese do método utilizado. Na avaliação predominam perguntas predeterminadas que recebem respostas prontas. Refiro, ligeiramente, que o paradigma escolanovista representou sensível avanço. Contudo, tal experiência não foi utilizada de modo amplo por deficiência estrutural do sistema escolar vigente. De outro lado, o modelo tecnicista preocupou-se, sempre, apenas, em atender ao mercado, tornando-se, ao meu ver, uma forma unilateral de observar o fenômeno da educação, não procurando, assim, aliar a competência técnica à competência política.

\section{PARADIGMA EMERGENTE E A PRODUÇÃO DO CONHECIMENTO}

A mudança de paradigma no campo da ciência, como antes demonstrado, provoca a necessidade de uma nova perspectiva no campo da educação. A reprodução do conhecimento há de ceder espaço para a denominada produção do conhecimento, o que é coisa completamente diferente.

A esse respeito, BEHRENS ${ }^{7}$ adverte que para alicerçar uma prática pedagógica compatível com as mudanças paradigmáticas da ciência, o paradigma emergente deve constituir uma aliança, formando uma verdadeira teia, com a visão sistêmica ou holística, com a abordagem progressista e com o ensino com pesquisa. Essa aliança se justifica e se torna necessária em função das características de cada abordagem.

A visão sistêmica ou holística foge da fragmentação do conhecimento, para prestigiar sempre a visão do todo, observando o homem como um complexo, ou seja, em suas inteligências múltiplas. Em suma: o homem total.

A abordagem progressista está ligada, intimamente, com o aspecto da transformação social. Há, neste caso, um entroncamento entre o individual e o social. Incita ao diálogo, à discussão e ao trabalho coletivo, às parcerias e participação crítica e reflexiva de alunos e professores.

E, por fim, o ensino com pesquisa tem em conta professores e alunos como pesquisadores e produtores do seu próprio conhecimento. Não apenas pesquisar para repetir. Mas, acima de tudo, desenvolver a pesquisa como maneira correta de formação de um substratum para a elaboração de futura produção própria. 


\section{O ENSINO DO DIREITO E O PARADIGMA EMERGENTE}

O último tópico do presente trabalho cuida do ensino do direito em relação ao paradigma emergente.

Assunto difícil. A minha experiência de mais de vinte anos lidando com o Direito, como professor, advogado e magistrado, me autorizam a dizer: o profissional do Direito é altamente conservador. Extremamente formal. Obediente à rígida hierarquia. Avesso - por demais - a mudanças que impliquem em alteração na sua conduta profissional. Por esse motivo, toda e qualquer mudança causa, de logo, profunda urticária no profissional ligado ao exercício do Direito.

Não me parece, assim, tarefa fácil a mudança de paradigma no ensino do Direito. Todavia, como tudo na vida caminha para a frente (não obstante alguns aparentes retrocessos), pois o homem carrega em sua intimidade a fatalidade da evolução, penso que o Direito, também, será conduzido pelos mesmos ventos que deverão embalar a educação de modo geral.

Pois bem. O ensino para a produção do conhecimento enseja, como visto anteriormente, uma visão holística, uma abordagem progressista e o ensino com pesquisa.

\subsection{A visão holística}

A visão holística pretende recuperar uma perspectiva do todo. Afirma BEHRENS $^{8}$ que o grande desafio da visão holística é a superação do saber fragmentado, que foi dividido na escola em disciplinas isoladas. No ensino do Direito não poderia ser diferente. Porém, a ciência do Direito é una. Não pode ser compartimentada, sob pena de grave desvio de perspectiva em relação ao todo. É impossível estudar o fenômeno jurídico por meio do exame de ramos isolados ou de institutos desconectados do sistema. Vale dizer: aqui, como nas demais ciências, as propriedades das partes somente podem ser compreendidas a partir da organização do todo. Assim, o ensino do Direito deve incorporar essa forma de pensamento, restabelecendo a visão de todo. Nesse contexto, o professor é extremamente significativo. HORÁCIO WANDERLEI RODRIGUES, ${ }^{9}$ a respeito do docente atual, teve a oportunidade de dizer: "um poço de narcisismo, egocentrismo e auto-suficiência. Esta parece ser, em muitos casos, a postura do professor de Direito. Postura que gera uma relação autoritária e vertical - um verdadeiro monólogo". Esse tipo de professor não terá mais espaço de atuação no modelo de ensino que se aproxima. Ou se modifica ou desaparece para sempre. Em suma: o professor, na visão sistêmica, precisa recuperar, no aluno, valores perdidos e assim, segundo CARDOSO, ${ }^{10}$ "educar significa utilizar práticas pedagógicas com integração intercultural e a visão interplanetária das coisas, em nome da paz e da unidade do mundo". De outro lado, nessa forma de ver o mundo, o aluno deve ser compreendido

8 BEHRENS, op. cit., p. 63/64.

9 Ensino Jurídico para que(m)? Tópicos para análise e reflexão. In: OAB Ensino Jurídico - Diagnóstico - Perspectivas - Propostas. 2. ed. Brasília: Cons. Fed. OAB, 1996.

10 CARDOSO, op. cit., p. 53. 
como um ser complexo, mas, de outra parte, dotado de individualidade que precisa ser respeitada. Ou seja: o aluno como ser humano é dotado de uma realidade espiritual que o diferencia de todos os demais. Como diz BEHRENS" "o aluno precisa ser considerado em suas inteligências múltiplas e pelos dois lados do cérebro".

No que atine ao método, o que se busca é uma prática pedagógica crítica, produtiva, reflexiva e transformadora. Nada disto acontece no ensino do Direito. Pelo contrário. O conhecimento escorre do professor sem qualquer participação do aluno e, via de conseqüência, sem qualquer conduta crítica de parte deste. São as conhecidíssimas aulas magistrais, onde o docente exerce (crivado de vaidade) os seus dotes de expositor, de profundo conhecedor da matéria, totalmente despreocupado com o aprendizado de parte do aluno. Por fim, na visão holística, a avaliação tem como alvo, fundamentalmente, o crescimento gradativo do aluno. Na verdade, a avaliação é resultado de um processo que não tem e nem pode ter conteúdo punitivo, como acontece, não raro, onde o professor exerce, quando contrariado, uma certa forma de vingança contra seus alunos.

\section{2 $\mathrm{O}$ paradigma progressista}

O paradigma progressista está conectado com uma procura de transformação social. Assim, o ensino deve proporcionar uma prática pedagógica crítica, reflexiva e transformadora.

Nessa perspectiva, a escola deve ser um ambiente onde seja possível o exercício constante de uma atividade libertadora, democrática, dialógica e crítica. A escola de Direito sempre foi avessa a estas proposições. É bem verdade que o ensino no Brasil, em sua totalidade, serviu ao regime do momento e ao ditador de plantão. Não havia, assim, prática democrática. $\mathrm{O}$ ensino deveria refletir as linhas mestras do regime político imposto. Assim, como o regime era autoritário, o ensino não poderia ser diferente. Enraizou-se, portanto, no ensino do Direito, uma prática pedagógica autoritária, não cedendo espaço para o diálogo, para a crítica, ofuscando, de outra parte, a possibilidade de uma ação libertadora e democrática. Esse pano de fundo gerou uma visão individualista do mundo que contamina, de modo profundo, a todos que lidam com fenômeno jurídico.

Passo a examinar, agora, o papel do professor, do aluno e a metodologia numa perspectiva progressista.

O professor, como sujeito do processo, estabelece uma relação horizontal com os alunos e busca, sempre, o diálogo, repelindo toda forma de repressão no processo e possibilitando a vivência grupal. No ensino do Direito nada disto acontece, lamentavelmente. O docente cria uma relação verticalizada (tanto isto é certo que determinadas escolas mantém o tradicional estrado para materializar a situação de inferioridade em que se encontra o discente) vendo o aluno como alguém que suplica a dádiva de receber o conhecimento que somente ele (o professor) detém. 
De outra parte, o diálogo somente existe quando o aluno concorda com a lição recebida do professor, como se isto não fosse, na verdade, uma forma de monólogo disfarçado. A verdade é que não existe aula dialógica. É dizer: o professor de Direito não estabelece qualquer aliança com o aluno, na busca de uma convivência participativa, geradora de crescimento para todos os envolvidos no processo de aprendizagem. Desgraçadamente, na atualidade, o aluno é objeto e somente o professor é sujeito na relação de aprendizagem. Esquecemos, todos, de uma premissa fundamental: o aprendizado é via de mão dupla. Sem aluno, não há professor e aluno ausente, amorfo, não participativo, desinteressado, não é aluno, mas mero espectador de alguém que apresenta o seu texto, corretamente decorado, recebe os aplausos e vai embora, deixando um imenso vazio no objeto que permanece na sala de aprendizado.

O aluno na abordagem progressista é participante efetivo do processo educativo. Confesso que prefiro a expressão aprendiz, pois me parece mais significativa do que aluno. Aprendiz é aquele que está ligado, de modo indissociável, ao ato de aprender. É no aprendiz que o processo de aprendizagem está centrado. Aqui, também, o ensino do Direito está em elevado débito com a sociedade. O aluno (uso a expressão, apenas, porque consagrada) é objeto. Diria mais. Em alguns casos é considerado coisa, mero elemento contábil, objeto de uma relação de mercancia de parte das instituições de ensino particular. De qualquer forma, no aspecto pedagógico, a desejada relação dialógica e amorosa, na saborosa expressão de FREIRE, está longe de acontecer no âmbito do ensino do direito

O método no ensino do direito, de sua parte, encontra-se totalmente superado. Neste sentido a Comissão de Ciência e Ensino Jurídico da OAB (1996: 11) ${ }^{12}$ afirma que existe uma preocupação com a substituição do verbalismo, numa recuperação metodológica, capaz de resgatar a "importância de se ensinar o aluno a pensar". Em outro trecho a mesma comissão conclui que os currículos jurídicos são exageradamente normativos permitindo a transmissão de um conhecimento genérico, dogmático e pouco dirigido para a solução de problemas, sendo carentes, de outra parte, de uma visão de interdisciplinariedade. De fato, é preciso admitir, de logo, que o ensino do direito encontra-se divorciado da realidade social. Impera um positivismo de superfície, na feliz expressão de FÁBIO COMPARATO, citado por WALTER CLAUDIUS ROTHENBURG. ${ }^{13}$ Cumpre salientar, no particular, o que consta do Parecer de 1981, aprovado no Instituto dos Advogados Brasileiros, quando afirma que o aluno deve ser capaz não apenas de reproduzir o conhecimento por meio de suas ações ou ensinamentos a terceiro, mas, especialmente, de produzir novos conhecimentos. Essa conclusão se afina com a abordagem progressista, que visa à produção do conhecimento e provoca a reflexão crítica na e para a ação. ${ }^{14}$ Ao que parece, pelo menos, a OAB mantém constante preocupação com o ensino do Direito. Algumas universidades, entre as quais a Pontifícia Universidade Católica do Paraná, começam a despertar para a nova realidade. Tal

12 Op. cit. na nota 9, 1996: 11.

13 Princípios constitucionais. Fabris, 1999, p. 14.

14 BEHRENS, op. cit., p. 84. 
despertamento, contudo, deve contaminar toda a educação do Brasil para que surja uma nova mentalidade com real progresso para o povo no que atine ao direito constitucionalmente assegurado à educação e à cultura.

A avaliação na abordagem progressista é contínua, processual e transformadora. No ensino do Direito, a avaliação não é contínua, muito menos processual e transformadora. Prevalece, ainda, o velho e perverso sistema de provas bimestrais. Não há caráter de processualidade e nem timbre de transformação. Ao meu sentir, a avaliação no ensino do Direito é mera imposição da escola e dever do qual o professor procura se livrar com a maior rapidez possível, sem qualquer preocupação com o aspecto relativo à aprendizagem do aluno. É imperativa uma reformulação imediata dos métodos de avaliação, pois, como utilizados, nada significam. Nada avaliam. Apenas servem como uma forma de jogo onde o aluno devolve para o professor aquilo que decorou.

\subsection{Paradigma do ensino com pesquisa}

Por fim, cumpre examinar o paradigma do ensino com pesquisa. O ensino com pesquisa impõe o desafio de domar a informação, submetendo-a a um processo interpretativo e, a partir desse dado, produzir novas informações. Em estudo antes citado, a Comissão de Ciência e Ensino Jurídico da OAB teve a oportunidade de esclarecer que não se pesquisa nos cursos de Direito, repete-se. Não se pratica nos cursos jurídicos, comenta-se. Daí a necessidade de um aprofundamento dos estudos dogmáticos, do desenvolvimento da pesquisa jurídica, da introdução do tratamento interdisciplinar dos conceitos jurídicos e de uma contextualização dos estudos da dogmática jurídica. ${ }^{15}$

Nesse contexto, o professor deve ser o orquestrador da construção do conhecimento. No ensino do Direito prevalece, ainda, a figura do professor conservador, dono do conhecimento. Não há qualquer participação do aluno no projeto pedagógico do professor (se é que ele existe). Pelo contrário: o programa é confeccionado pelo professor e imposto, unilateralmente, ao aluno, que somente possui uma alternativa, ou seja, aceitar, pacientemente, o conteúdo oferecido, como algo acabado, sem qualquer possibilidade de nele interferir.

No que se refere ao aluno, altera-se, por completo, sua situação, pois abandona a sua condição de objeto para se tornar sujeito do processo educacional, e não mero espectador. A respeito do assunto, escreveu PEDRO DEMO: ${ }^{16}$

"É fundamental que os alunos escrevam, redijam, coloquem no papel o que querem dizer e fazer, sobretudo que alcancem a capacidade de formular ... Formular, elaborar são termos essenciais da formação do sujeito, porque significam propriamente a competência, à medida que se supera a recepção

16 DEMO, Pedro. Pesquisa e construção do conhecimento. Metodologia científica no caminho de Habermas. Rio de Janeiro: Tempo Brasileiro, 1994: 28/29 e 54/55. 
passiva do conhecimento, passando a participar como sujeito capaz de propor e contrapor. Aprende a duvidar, a perguntar, a querer saber, sempre mais e melhor. A partir daí, surge o desafio da elaboração própria, através da qual o sujeito que desperta começa a ganhar forma, expressão, contorno, perfil. Deixase para trás a condição de objeto."

A metodologia tem como objetivo a produção do conhecimento. Pesquisa, contudo, não é mera cópia. Vale dizer: o ensino com pesquisa pressupõe a capacidade do aluno em aprisionar o conteúdo do material pesquisado, submetendo-o a uma análise crítica e reflexiva para gerar, posteriormente, a produção de um trabalho próprio. No ensino do Direito o aluno - na condição de objeto - é mero copiador de textos, sem nenhum proveito, pois, alcançado o objetivo da pesquisa (geralmente a atribuição de nota), nada resta, nada fica, e o aluno encontra-se vazio, exatamente como estava antes de iniciar a pesquisa.

Acredito que é o momento de mudar, para melhor. A afirmação de novos paradigmas representa, sem dúvida, esperança. Como diz WARAT, ${ }^{17}$ aprender direito é ser criativo, aberto ao novo e predisposto à solidariedade. O resto é crise.

\section{REFERÊNCIAS BIBLIOGRÁFICAS}

BEHRENS, Marilda Aparecida. O paradigma emergente e a prática pedagógica. 1. ed. Curitiba: Champagnat Universitária, 1999.

BRANDÃO, DENIS \& CREMA, Roberto. O Novo paradigma holistico. São Paulo: Summus, 1991.

CAPRA, Fritjaof. A teia da vida. Uma nova concepção científica dos sistemas vivos. São Paulo: Cultrix, 1996.

CARDOSO, Clodoaldo Meneguello. A canção da inteireza. Uma visão holística da educação. São Paulo: Summus, 1995.

DEMO, Pedro. Pesquisa e construção do conhecimento. Metodologia científica no caminho de Habermas. Rio de Janeiro: Tempo Brasileiro, 1994.

KUHN, Thomas. A estrutura da revolução científica. 4. ed. São Paulo: Perspectiva, 1996.

RODRIGUES, Horácio Wanderlei. Ensino Jurídico para que(m)? Tópicos para análise e reflexão. In: OAB ensino jurídico - Diagnóstico - Perspectivas - Propostas. 2. ed. Brasília: Conselho Federal da OAB, 1996.

ROTHENBURG, Walter Claudius. Principios constitucionais. Porto Alegre: Sergio Antonio Fabris, 1999.

WARAT, Luis Alberto. Comissões pedagógicas diante da crise do ensino jurídico. 